\title{
CONTRIBUIÇÕES CULTURAIS DE BRASILEIROS NO JAPÃO E JAPONESES NO BRASIL, POR MEIO DA EDUCAÇÃO INFORMAL E LAZER
}

RESUMO: Baseia-se, em parte, no estudo efetuado no Doutorado', com o tema: "Lazer, educação informal e traços culturais do migrante brasileiro que permanece temporariamente no Japão", e com o subtema: "Diálogo de traços étnico-culturais e de lazer entre brasileiros no Japão e japoneses no Brasil" No referido trabalho, além da bibliografia consultada, visitas técnicas, aplicaram-se questionários e entrevistas a brasileiros retornados do Japão, cuja vivência assemelhou-se à dos imigrantes japoneses no Brasil. Observaram-se impactos positivos e negativos, resultando em contribuições culturais nos países de destino, no caso, Brasil e Japão. Tais contribuições transmitidas por meio da educação informal e do lazer estão reformatando traços culturais nesses paises.

PALAVRAS-CHAVE: Contribuições culturais; educação informal; lazer; Brasil; Japão.

\section{Introdução}

O presente tema baseia-se no estudo efetuado no Doutorado, com o tema "Lazer, educação informal e traços culturais do migrante brasileiro que permanece temporariamente no Japão" e tem como subtema: "Diálogo de traços étnicoculturais e de lazer entre brasileiros no Japão e japoneses no Brasil" Nele foram observados impactos positivos e negativos, resultando em contribuições culturais nos países de destino, no caso, Brasil e Japão. O conjunto dessas contribuições em costumes, valores culturais, alimentação e lazer no tempo livre, língua e linguagem, 
entre outras, está reformatando traços culturais nesses países, por meio da educação informal.

Inicialmente, colocam-se conceitos de lazer e educação informal, trabalhando os subtemas, como impressões culturais, costumes, língua e linguagem, em forma de diálogo cultural entre brasileiros no Japão e japoneses no Brasil. Em seguida, abordam-se relações sociais e adoção da brasilidade pelos japoneses. E, por fim, são elaboradas algumas considerações finais.

\section{Conceituação}

O lazer compreende atividades que levam à diversão, ao entretenimento, ao relaxamento e à aprendizagem para aprimoramento da personalidade, conforme Dumazedier $(1972,1976)$. E, também ao desenvolvimento de relações de amizade e/ou de relações sociais, de auto-realização e de felicidade. São atividades praticadas que conduzem ao bem estar físico e mental, para satisfação das necessidades individuais, supostamente salutares ou benéficas e que não causam stress.

Enfim, lazer deve ser desenvolvido no tempo de que a pessoa dispuser, por livre e espontânea vontade, sem pressão ou qualquer tipo de coação, no espaço de sua escolha.

Em relação à educação informal, esta é a aprendizagem que ocorre de maneira espontânea e natural, por meio da educação familiar e/ou no seio de uma comunidade e/ou outro agente formador do qual o educando faz parte. Portanto, ocorre ao longo da trajetória de vida pessoal, social, e das escolhas dos estilos de vida, e por ela, são transmitidos os costumes, linguagens e ritos do meio ambiente em que se vive.

Como foram as impressões culturais dos migrantes e dos imigrantes?

\section{Impressões culturais}

Os primeiros imigrantes japoneses no Brasil foram considerados de "dificil assimilação tanto pelas autoridades, quanto pela imprensa" brasileira e pelo povo em geral, pois eram portadores "de língua, hábitos e costumes dos quais não se desligavam dada sua pequena capacidade de assimilação" (NOGUEIRA, 1984:150).

A vivência de japoneses no Brasil, nos primórdios da imigração, em suas 'colônias' rurais, isolados e confinados com seus pares, manteve seus costumes e valores congelados no tempo. E, mesmo após a criação de associações, que eram inicialmente limitadas a japoneses, foram tachados de formadores de quistos sociais, com o uso da língua, padrões de comportamento e símbolos particulares, o que os afastava de outras etnias, conforme Vieira (1973: 165). 
Essa situação ocasionou, nos primeiros tempos, a dificuldade de integração dos japoneses com os brasileiros e a aprendizagem da língua e costumes. Por outro lado, os imigrantes conseguiram manter vários costumes, valores e conhecimentos japoneses por anos num país alienígena ao de sua origem ${ }^{1}$

Já os brasileiros ${ }^{2}$ no Japão tiveram comunicação e contatos diretos com japoneses no trabalho e na vida cotidiana, vivenciando a cultura do país logo que chegaram, em geral em zonas urbanizadas, aprendendo forçosamente a língua, linguagens e costumes.

Percebeu-se que os japoneses não olham com bons olhos os migrantes brasileiros que se transferem ao Japão para ganhar a vida, mas se esquecem de que os primeiros imigrantes conterrâneos seus procuraram o Brasil numa época difícil de vida no Japão, e também passaram por muitas dificuldades. Criaram escolas de língua japonesa para preparar seus filhos para o retorno ao Japão, assim como estão fazendo brasileiros no Japão, com a criação de escolas brasileiras ${ }^{3}$ e manutenção de seus padrões de valores para quando retornarem ao Brasil.

Conforme Handa (1973:400), o choque cultural dos primeiros imigrantes era tão grande, que tinham dificuldades de dar um toque estético a suas vidas, pois tiveram que morar em casas sem tatami, substituir o quimono por roupa ocidental, o hashi por garfo e beber café em lugar de chá.

Para mostrar um diferencial cultural tomou-se como exemplo a entrevista de um brasileiro que observou o encontro entre um pai e sua filha no aeroporto, estranhando seus gestos muito formais, uma vez que os brasileiros expressam seus sentimentos com risos, abraços, alegria e até choram quando encontram seus entes queridos. Os japoneses ao contrário, são reservados, polidos e não costumam expor seus sentimentos diante de outros, passando uma impressão de frieza.

Portanto, há impressões culturais características entre brasileiros e japoneses que precisam ser conhecidas.

1. A imigração japonesa começou em $1908 \mathrm{e}$, em 1973 chegaram os últimos navios trazendo imigrantes japoneses ao Brasil. Eram os navios Brasil-Maru e Nippon-Maru, encerrando a imigração por navios (Nakasumi e Yamashiro, 1992: 434). A partir dessa data, a natureza da imigração se modificou. A aceitação de imigrantes pelo governo brasileiro se tornou severa de 1979 a 1980, e "14 pedidos de entrada de imigrantes técnicoindustriais apresentados pelo governo japonês" foram recusados com alegação de que não preenchiam requisitos necessários (Nakasumi e Yamashiro, 1992: 419). Mas a causa principal era, na verdade, o "aumento do desemprego em conseqüência da recessão econômica brasileira” (Nakasumi e Yamashiro, 1992: 419).

2. Brasileiros começaram a procurar o Japão na década de 1980 , intensificando-se essa procura a partir de 1988.

3. Já existem cerca de 87 escolas reconhecidas pelo MEC do Brasil, dentre as quais 19 de ensino médio (São Paulo Shimbun. 24/01/2004, p.6 e 08/04/2006, p.5). 


\section{Costumes}

Verificou-se que parte dos sujeitos brasileiros no Japão demonstrou conhecimento dos costumes e de valores recebidos dos pais, parentes e/ou comunidade a que pertenceu ou que freqüentou. Portanto, instruções, orientações e valores recebidos por meio da educação informal, internalizados nas pessoas, facilitaram a compreensão e apreensão de algumas regras sociais aceitas e bem recebidas na sociedade japonesa. E, ao retornar ao Brasil, alguns brasileiros passaram até a criticar características culturais de sua origem, como se fossem japoneses, pois passaram a ver, aceitar e praticar alguns costumes daquele povo.

\subsection{Valores culturais}

Aprenderam a dialogar para a resolução de problemas e a retribuir, quando necessário, de maneira abrasileirada, simples e espontânea. Alguns disseram que haviam recebido rigorosa educação, desde a infância, com aquisição de alguns costumes, como o da educação ancestral do Japão, com o lema 'meiwakuo-kakeruna'4, como parte da vida cotidiana.

- Alguns apontaram valores aprendidos no Japão, como:

Cooperação com o grupo e retribuição de favores.

Mudança nos costumes e valores.

Modificação da língua e linguagem.

- Respeito a horários, e à rigorosa hierarquia entre veteranos e novatos.

- Respeito ao cuidado com os mais velhos.

Por sua vez, os imigrantes japoneses apresentaram algumas características culturais peculiares por estarem "confinados no âmbito de uma sociedade cultural e economicamente diferente" da sua, tendo como referencial a vida familiar e o lar como seu único mundo. Esse fato se refletia no "desejo de manter, sob estrito controle, a família, que é seu mundo único e exclusivo". E, por meio do ensino de língua japonesa, tentavam criar a base de comunicação de seus valores e costumes entre seus pares, conforme Tsukamoto (1973: 26-27). Porém, percebeu-se que a língua e a linguagem dos japoneses do Brasil não acompanharam a dinâmica da língua japonesa do Japão.

Os pais japoneses no Brasil tinham uma posição estratégica de autoridade sobre os filhos, expressa em termos de uma dívida, intitulada on, em que os filhos são devedores e se esforçam por retribuir eternamente o débito que têm com os superiores, de acordo com

4. Meiwakuo-kakeruna: não dar trabalho aos outros, nem desonrar o nome da família. 
Cardoso (1995: 105-106). Assim, a lealdade devia estar sempre presente, o que implicava retribuir favores importantes.

Isso explica a razão do respeito hierárquico existente nas relações familiares, empresariais, e nas demais instituições, assim como a lealdade recomendável de subordinados para com a empresa. Dessa forma, a relação entre veteranos e novatos é de suma importância na sociedade japonesa, pois os novatos têm débito eterno em relação aos veteranos, que devem zelar e cuidar deles, da mesma forma. Todas essas categorias de respeito, hierarquia e procedimentos tornam o país pleno de regras formais aos olhos dos migrantes brasileiros, no Japão.

Muitos desses costumes, hábitos e atitudes passaram dos imigrantes japoneses para seus filhos por meio da educação informal, no Brasil.

\subsection{Alimentação}

Em relação à alimentação, tanto para brasileiros no Japão como para japoneses no Brasil houve dificuldades. Os primeiros imigrantes japoneses sentiram a falta de produtos à base de soja, do arroz catete cozido sem sal e do feijão para fazer seus doces. A alimentação deles era mais leve em relação à culinária do Brasil, país tropical (quente na maior parte do ano), e eles vieram para dar duro no trabalho braçal, com muito suor. Portanto, a alimentação mais salgada e forte do brasileiro tinha sua razão de ser. Assim, foram muitos os primeiros imigrantes a sofrer de doenças gastrointestinais e dermatológicas por se alimentarem de maneira inadequada para o clima, pelo tipo do trabalho e falta de adaptação à culinária brasileira, pois não se alimentavam nem como os brasileiros e nem como os japoneses.

Já os brasileiros no Japão foram trabalhar em geral nas áreas urbanas, com maior facilidade de obter ingredientes variados, produtos semi-acabados ou mesmo pratos prontos, mas não deixaram de sentir impactos diferenciais na alimentação, tentando solucionar com maior rapidez esse problema com a importação de vários produtos do Brasil.

Isso mostra que nossa memória grava as experiências vividas fisicamente, como a da aprendizagem gustativa, a do sabor e a do sensorial, agregadas a valores culturais aprendidos, que não são esquecidos. Também explica a existência e resistência do bairro da Liberdade (SP), onde começou a fixação urbana de imigrantes japoneses, bairro que faz lembrar e relembrar suas raizes culturais e a ele retornar sempre.

Os primeiros imigrantes japoneses no Brasil tentaram adaptar o feijão brasileiro para elaborar doce, pois estavam acostumados a consumir doce de feijão no Japão, embora de espécie diferente. Contrariamente, os brasileiros no Japão tentam adaptar o feijão próprio para fazer doces para o preparo do caldo de feijão como é feito no Brasil, para consumi- 
lo com o arroz. Um deles, por exemplo, preparou-o no denki-gama ${ }^{5}$, pois não encontrou panela de pressão no Japão.

Conforme Nogueira (1984: 158), a alimentação do imigrante japonês no Brasil, na primeira fase, era constituída quase inteiramente de elementos locais, porém, a partir de 1918, ele consegue fazer alguns pratos japoneses em razão da melhoria de suas condições econômicas e também em virtude do aparecimento da indústria e do comércio de produtos japoneses. Somente após 1925, na terceira fase, a dieta "enriquece-se sobremaneira, em razão da dualidade de elementos brasileiros e japoneses nas refeições"

E, dentre as adaptações, a grande descoberta dos imigrantes japoneses no Brasil foi a de usar o fubá como substituto do farelo de arroz, chamado de nuka missô, para preparar o tsukemono ou picles japonês, cuja receita até hoje é adotada, em razão do cheiro desagradável do verdadeiro nuka missô. (HANDA,1987: 542).

Quanto às famílias de nikkeis no Brasil, que já se haviam acostumado à comida, com o passar dos tempos passaram a elaborar "um padrão alimentar duplo: almoço à brasileira e, dentro do possível, jantar à japonesa". Combinavam arroz branco, feijão, bife, salada ou tsukemono, e às vezes, missôshiru ${ }^{6}$ no jantar. Muitos imigrantes não ficavam sossegados enquanto não degustassem, após a comida ocidental, um pouco de arroz branco, em forma de ochazuke ou arroz branco regado com chá verde, conforme Handa (1987: 538).

Quanto aos brasileiros no Japão, lá passou-se a vender, feijão, pó de café, verduras e legumes como chuchu, abobrinha, couve-manteiga, beterraba etc., mas, parece que a jabuticaba ainda não fazia parte dos produtos importados no Japão, pois uma entrevistada disse que sentia saudade dessa fruta. Fazem pedidos pelo telefone e depois de dois a três dias recebem em casa. A partir de 1988, com a intensificação da entrada de brasileiros no Japão, aparecem mordomias em bairros onde há maior número de brasileiros, como supermercados, lojas vans, locadoras de $\mathrm{CD}$ e vídeos, danceterias, etc.

Dentre os produtos alimentares e refeições prontas mais citados na compra ou de que sentiam saudade, em primeiro lugar estava o feijão (um pouco mais da metade dos entrevistados), tendo sido mencionados ainda por alguns feijoada, coxinha e pastel. Também, adquirem com maior facilidade, desde farofa, arroz brasileiro, vinagre, polenta, farinha de trigo, maisena, curry ${ }^{7}$ brasileiro, leite condensado, pacote de salgadinhos brasileiros, lámen Miojo brasileiro (por ter sabor adaptado ao brasileiro), creme de leite, macarrão, carne seca, doces brasileiros. Enfim, têm acesso a uma infinidade de produtos alimentícios. Muitos

5. Denki-gama: Panela elétrica automática para fazer arroz.

6. Missoshiru é a sopa feita de missô, com acréscimo de ingredientes variados, conforme o gosto da pessoa.

7. Curry é um condimento de origem indiana, feito com a mistura de vários cheiros e aromas, muito apreciado pelos japoneses, que é também produzido no Japão. 
dos produtos citados acima têm o equivalente no mercado japonês, porém os brasileiros preferem comprar os importados do Brasil.

Alguns entrevistados disseram que costumavam comprar café em pó para preparar e tomar café coado e feito na hora, pois o café do Japão é aguado, e seu preparo é diferente. Também o molho de tomate da marca 'Pomarola' é procurado por seu sabor, pois os molhos japoneses são em geral adocicados. E, em relação ao prato feito e composto por arroz, feijão, batata e bife acebolado, foi lembrado por alguns dos entrevistados, pois um deles disse que sentia falta daquela comida caseira brasileira.

Os brasileiros disseram que costumavam comprar carne importada do Brasil em açougues brasileiros, ou fazendo pedido pelo telefone, pois o corte da carne é diferente daquele dos açougues japoneses, principalmente para fazer churrasco. Mas essa situação está levando os brasileiros a serem acometidos de doenças de nosso século, pois foi constatada entre eles a presença de alto índice de colesterol e problemas de obesidade, conforme a pesquisadora Schwingel ${ }^{8}$.

Viver no Brasil sendo japonês ou no Japão sendo brasileiro não é mais empecilho em relação aos produtos alimentícios e demais itens arrolados pelos migrantes.

Alguns pratos da culinária brasileira passaram a ser feitos com ingredientes japoneses adaptados, reinventados e adotados. Assim, a massa para guioza ${ }^{9}$ era recheada com ingredientes e frita como se fosse pastel, à moda brasileira. Costumavam fazer pizza, na frigideira, no fogão a gás, pois não havia forno, colocando molho de tomate e queijo derretido por cima. Substituíram o bacalhau por salmão defumado para fazer a "torta de bacalhau" Preparavam bolo com farinha de trigo brasileira, pois a japonesa era diferente. Assim, conseguiam preparar bolos, como o de nozes e outros, num mini-forno, para vender em pedaços para os colegas de trabalho japoneses que os compravam por serem diferentes.

Quanto aos pratos preferidos e adotados pelos brasileiros no Japão eram: oniguiri ${ }^{10}$ e lámen, mas alguns achavam mais prático o cup-lamen no cotidiano. Apreciavam também o curry rice, niku-man ${ }^{11}$, sushi, udon e sashimi. Estes últimos pratos, muitas vezes com ingredientes de peixe cru, entraram no gosto de brasileiros. O missôshiru, que é uma sopa à base de soja, típica da alimentação japonesa, sempre acompanhando o arroz branco, passou a ser adotado por muitos brasileiros como se fosse o correspondente ao arroz e feijão, uma vez que alguns não conseguiram encarar o natto, que é feito também de soja, mas fermentado.

8. Palestra proferida por Andiara Schwingel, na Sociedade Brasileira de Cultura Japonesa, no dia 15 de Abril de 2005, com o tema "Brasileiros no Japão: saúde e estilo de vida"

9. Guioza: pastel, tipo chinês, com preparo de massa diferente da do pastel brasileiro.

10. Bolinho de arroz.

11. Niku-man é um bolinho recheado com carne moída de boi, frango ou porco, comida de origem chinesa. 
Portanto, assimilaram-se pratos japoneses, e também receitas brasileiras foram introduzidas no Japão, numa tentativa de tornar a nova vida mais amena.

\subsection{Lazer no tempo livre ${ }^{I 2}$}

Muitos passearam quando possível, enquanto outros aproveitaram bastante, participando dos piqueniques promovidos pela chefia nos finais de semana e também fazendo acampamento. Passearam com colegas brasileiros e permaneciam na região onde trabalhavam, mas iam uma vez ou outra para grandes centros urbanos a fim de conhecêlos. Alguns viajaram com os que tinham carro, nas folgas do trabalho e quando podiam.

Outros se dedicaram às atividades de encontros com amigos em barzinhos ou saíam à noite para o centro da cidade, pedindo informações. Algumas vezes saíam para danceterias e conversa com o povo em geral, tentando participar do lazer cotidiano dos japoneses ou íam ouvir música tocada ou mesmo ao karaokê, para ouvir e cantar.

Mas, alguns sujeitos aproveitaram o tempo livre para o aprimoramento da língua japonesa em 'escolinha' de língua japonesa voltada para estrangeiros, promovida pelos japoneses.

Todas essas práticas e participações têm exercido, como função principal, 'favorecer a amizade', o que se comprova pelos relatos das entrevistas, que revelam um constante contato espontâneo com colegas e amigos brasileiros, ou incentivado por eventos promovidos pelas empresas. Essa situação denota, de maneira indireta, a função social e formação do capital social, com a ampliação do conhecimento de situações de emprego de outros brasileiros, e mesmo para sondar um emprego melhor.

Por outro lado, os imigrantes japoneses que viviam na área rural brasileira, tinham como uma das atividades prazerosas o passeio pelo bairro da Liberdade, para encontrar 'outros rostos japoneses' e conversar em japonês, pois eram momentos de identidade com pessoas em situações semelhantes. Degustar a comida japonesa nos restaurantes, e vez ou outra pegar um cinema, assistir a um filme de mocinho e bandido, de fácil entendimento, mesmo para aqueles com dificuldades de entendimento da língua portuguesa, eram considerados programas agradáveis. No aniversário do imperador organizavam festas em homenagem ao aniversariante, com competição de sumô, espetáculos teatrais, undôkai ${ }^{13}$ e comes e bebes. A passagem do Ano Novo era

12. Baseado na palestra "Lazer do imigrante japonês no Brasil", um dos sub-capítulos do Mestrado da autora, apresentado resumidamente, junto à ABEJ, na Fundação Japão, publicado em Estudos Japoneses, n.25 2005 , p.71a 80 .

13. Undôkai: gincana poliesportiva. 
comemorada como momento de descanso, após duro trabalho anual, tendo sido adotada também a festa junina, como festa de inverno. Só muito tempo depois, alguns passaram a praticar o ikebana ${ }^{14} \mathrm{e}$ o cerimonial do chá.

Nas noites de sábado ou nos domingos à tarde, os imigrantes japoneses veteranos (senpai) e novatos (kôohai) costumavam se reunir para conversar, contar vantagens e queixarse da vida, comendo iguarias como feijão cozido no açúcar, café bem doce e ou pinga com peixe seco dessalgado na brasa. Introduziram o banho de furo ou ofurô ${ }^{15}$, improvisado em tambores de pinga vazios, onde podiam lavar todo o cansaço do dia, além de promover a higiene fisica. Alguns mais inspirados escreviam poemas, em tankas, exprimindo seus sentimentos acerca da vida que levavam.

Ainda, os imigrantes criaram associações com várias finalidades, como a de oferecer aulas de língua japonesa a fim de preparar os filhos, para quando retornassem ao Japão, além de dar espaço para resolução de problemas sociais de seu grupo de imigração. Algumas dessas associações, com o tempo foram se transformando em espaços recreativos e culturais, e dentro delas passaram a praticar gincana poliesportiva, os undôkai, festas de confraternização, de casamentos, esportes como sumô, beisebol ou sessões de oratória, e, nos seinen-kais ou associações de jovens, podiam trocar idéias com seus pares, ler desenhos em quadrinhos, os mangas, em língua japonesa.

Já, no Japão, em julho de $2006^{16}$ foram divulgadas duas iniciativas brasileiras: uma de mostra de Cinema Brasileiro e outra de Show de Mágicas. Estas exemplificam o contato de brasileiros com a cultura verde-amarela e algumas crianças tiveram oportunidade de ver filmes falados em português, passando por uma nova experiência. Também puderam apreciar em conjunto com os japoneses o "The Oriental Magic Show" do Brasil, que percorreu algumas cidades japonesas, com maior presença de brasileiros.

Esses exemplos mostram que tanto brasileiros no Japão como japoneses no Brasil organizam suas vidas entre trabalho e lazer, ocasionando mudanças no cenário local de destino e administram seus estresses da vida.

\section{Lingua e linguagem}

Nessa questão, quase metade dos sujeitos da amostra não teve dificuldades com relação à língua falada ou entendimento da linguagem e alguns não conseguiam lembrar-

14. Ikebana: Arte de florir.

15. Ofurô, já faz parte de alguns spas brasileiros para relaxamento.

16. Cf. Hayama e Souza, "A descoberta do cinema" (p.44-45) e Kojima, "Mágica no Japão" (48-49), Made in Japan, n. 106, ano 9. 
se de nenhuma ocorrência de mau entendimento lingüístico, enquanto outros sentiram que o objeto da fala ou do referente não estava na mesma sintonia, pois o contexto social referido é diferente, situações de não correspondência dos elementos de comunicação, sentidas e observadas em suas vivências de origem ${ }^{17}$ Portanto, a dificuldade de comunicação ocorre entre pessoas que desconhecem o contexto social vivenciado pelo outro, que não se assemelha ao seu.

Dessa forma, concluímos que $50 \%$ dos entrevistados tiveram ou tinham alguma dificuldade de língua ou haviam experimentado diferenciais na comunicação da linguagem. E o estudo dessa dificuldade mostrou que ela não estava longe daquela dos imigrantes japoneses no Brasil.

A comunicação lingüística era um dos principais problemas da coletividade japonesa no Brasil. $O$ japonês não tinha a facilidade $\mathrm{e}$ a espontaneidade que outros povos tinham para entrar em contato com os brasileiros. O mal-estar causado por falta de maior conhecimento da língua no Brasil era grande até a década de 1930. Os imigrantes se queixavam por não conseguir expor seus pensamentos fluentemente e discutir com os brasileiros, o que resulta em freqüentes confusões, conforme Handa (1987: 143).

Já, os brasileiros da amostra citaram algumas confusões ocorridas, no Japão, em vista do desconhecimento da língua e linguagens:

- Por não conhecer a panela de fazer arroz em japonês, o denki-gama, que, literalmente, significa panela elétrica, um entrevistado traduziu como "gohan-nabe", que significa panela de arroz, o que causou muitos risos.

- A palavra pessoa emjaponês pronuncia-se ninguen, e em portuguêsé muito próxima da palavra ninguém, que significa exatamente a inexistência da pessoa, o que gerou muita confusão.

- O idioma aprendido pelos pais utilizava termos muito antiquados, e algumas expressões já não eram mais correntes no Japão; sendo assim, o brasileiro compreendia o que se falava pelo contexto, mas os japoneses não entendiam quando ele falava.

- Alguns entrevistados sentiam diferença na maneira de se expressar dos japoneses, pois os brasileiros falam com mais emoção e envolvimento.

Por outro lado, no Brasil, era freqüente os filhos mais desembaraçados ou os amigos atuarem como intérpretes. Muitos isseis não conseguiam se familiarizar com o uso do português, enquanto seus filhos falavam o português fora de casa e, voltando para o lar, eram obrigados a falar em língua japonesa.

17. Segundo Wurman (1991: 110), as palavras podem ter significados diversos entre pessoas, pois os contextos sociais vivenciados são diferentes e cada um faz em sua mente a imagem que lhe aprouver, relacionada às palavras, não havendo correspondência exata entre elas. 
Isso ocorreu com imigrantes japoneses no Brasil, situações em que os filhos sentiam constrangimento em relação aos pais que não falavam ou falavam o português muito mal. Da mesma forma, os filhos de brasileiros no Japão não gostam da atitude de seus pais, que não conseguem aprender a língua e linguagem japonesas. Portanto, a dificuldade encontrada pelos brasileiros é muito semelhante à dos imigrantes japoneses.

Também a adoção da língua portuguesa, gestos e posturas dos filhos de japoneses no Brasil foram alterando a fisionomia antes grave e muda para expressões mais abertas e expansivas como as dos demais brasileiros, até na maneira de contar as piadas, diz Saito (1977:21-23).

Todas essas situações resultaram em contribuições, pois muitos vocábulos da língua japonesa já fazem parte do dicionário português como sushi, shoyu, saquê, karaokê, sumô, judô etc., com empréstimos da língua japonesa no português do Brasil. Ocorrências semelhantes são observadas no contingente de brasileiros no Japão, onde começam a aparecer "mesclados no texto em japonês" palavras como: "churrasco, feijão, farinha, feijoada, couve, rodízio" e outras, segundo Kono (2002:197-207).

\section{Relações sociais e capital social}

Conforme depoimento das pessoas que permaneceram por maior tempo no Japão, há tendência de fixação definitiva nesse país, como aconteceu com os japoneses e seus descendentes no Brasil. Assim, os que têm essa intenção passam a participar de várias atividades e associações de bairros, juntamente com populações autóctones, para sua melhor integração, bem como a de sua família na comunidade local, tentando criar raízes e reforçar a rede de capital social.

Foi citado o exemplo de uma brasileira que mora há mais de 10 anos no Japão e tem mais amizade com japoneses do que com brasileiros, pois não pretende mais voltar para o Brasil, e mudou o foco de interesse para ser integrada na sociedade japonesa. E, uma das maneiras de se integrar à sociedade japonesa é passar a fazer parte de associações de bairro, tornando-se membro, com pagamento de uma taxa que vai custear os eventos, participando de reuniões e recebendo comunicados para várias atividades de bairro, tanto para adultos como para crianças, colaborando em sua organização. Como essas organizações têm canais de comunicação social com outras associações em rede, cria-se uma oportunidade de ampla relação de amizade e de capital social.

Essa preocupação vislumbrou-se também entre os imigrantes japoneses, quando resolveram permanecer e fixar-se no Brasil, com a derrota do Japão após a Segunda 
Guerra Mundial ${ }^{18}$ Foram então criadas as associações, e algumas delas se transformaram em clubes ${ }^{19}$.

\section{Adoção da brasilidade pelos japoneses}

Com base nas entrevistas tentou-se verificar, sob a ótica dos sujeitos da amostra, que tipos de adoções já ocorreram entre os japoneses. Constatou -se, que:

Alguns japoneses gostam de novidades, e então vão aos restaurantes brasileiros e, quando simpatizam, vão procurar lojas de conveniência de brasileiros e passam a adquirir produtos e a adotá-los. Segundo uma entrevistada, seus amigos japoneses passaram a apreciar a caipirinha. Também foi observado no refeitório da fábrica que muitos japoneses optavam pela comida brasileira oferecida no almoço, como feijão e arroz, que a cozinheira japonesa preparava. Alguns ainda passaram a gostar do churrasco, quando brasileiros preparavam, e outros aprenderam a consumir salada de almeirão, feijoada, frango assado, pão de queijo, pastéis, quibe, coxinha, que os brasileiros estão vendendo nas lanchonetes.

Em termos de churrascaria, o restaurante "Bacana", em Tóquio, é muito freqüentado pelos japoneses, enquanto o "Barbacoa", também em Tóquio, é procurado tanto por brasileiros como por japoneses. Isso demonstra a internacionalização da comida brasileira, do modo diferente de servir, o que acaba atraindo muitos simpatizantes.

Em relação a outros produtos brasileiros, verificou-se que japoneses gostam de comprar os "jeans" confeccionados no Brasil, pois os modelos são diferentes, além de o corte da calça valorizar o tipo de anatomia das brasileiras. Os modelos de lingerie também são procurados pelas japonesas e até as migrantes dominicanas passaram a encomendá-los, por intermédio de colegas, amigos ou parentes brasileiros, para ser enviados e revendidos. Também as camisetas "Hering" são revendidas, demonstrando que o paradigma da mulher brasileira tem seu espaço de vaidade e atrai os olhares tanto das jovens japonesas como de outras.

Quanto às relações sociais, alguns japoneses aprenderam aquele jeitinho do brasileiro de fazer amizade, com tapinha nas costas e gestos de camaradagem para

18. Os imigrantes japoneses transferem o foco de lealdade ao Japão e seu imperador para o Brasil, conforme Saito (1980:87), país que adotam para filhos e netos, substituindo o plano inicial de retorno para o país de origem pelo de permanência definitiva. Assim, mudam a atitude e comportamento, preocupando-se com a educação e preparação dos filhos para a vida no Brasil, melhorando o conforto no lar, tentando atingir o mesmo status da sociedade local em bens materiais, participação positiva na sociedade local, ingresso nas associações, clubes e intervenção política, e conseqüente busca pela cidadania brasileira e naturalização (Ikari, 2002:35).

19. Cf. estudo efetuado no mestrado (Ikari, 2002:105), das dez associações e clubes estudados, cinco foram criados na década de 1950, portanto, logo após a Segunda Guerra Mundial, com a finalidade de prepararem cidadãos brasileiros, acompanhando a educação dos filhos, e compartilhando com outros pais as mesmas preocupações. 
cumprimentar de maneira mais informal, dando a mão. Outros copiaram os trejeitos típicos dos brasileiros, como gestos para falar e expressar-se, quando agradecem ou pedem desculpas, por meio do jogo de futebol e da seleção brasileira, conforme a observação de um entrevistado.

Os eventos brasileiros também estão interferindo na mudança das paisagens locais, pois, ao mesmo tempo em que vários eventos de origem japonesa acontecem no bairro da Liberdade $^{20}$, estão ocorrendo no Japão as festas juninas e o Carnaval, logicamente, com leituras diferenciadas, reformatados e adaptados aos costumes e culturas das populações endógenas. Isso ratifica o poder dos fatos, que transpõem tempo e espaço, a razão do estudo sincrônico de dois espaços diferentes (Japão e Brasil), em tempos diversos, que se repetem pela similitude dos acontecimentos.

Portanto, "culturas híbridas" ${ }^{21}$ são notadas, onde há maior aglomeração de brasileiros no Japão, nesses 100 anos de imigração japonesa no Brasil. São bairros e cidades com características ecléticas, próprias do fenômeno intercultural. Nesses lugares, lojas, produtos, propagandas exógenas se misturam a restaurantes típicos, onde pessoas se encontram em eventos de seu povo e país, com um novo olhar, modificando as paisagens antes homogêneas das cidades japonesas com cultura hegemônica, que se soma à de outras etnias, transformando-a em diversidade cultural e multicultural; como ocorreu no Brasil, com os imigrantes japoneses e demais etnias.

\section{Considerações finais}

Essas contribuições culturais permanecerão para sempre, como legado, na dinâmica da formação do povo, estampadas na miscigenação e registradas nos diferenciais dos traços culturais dos lugares por onde os japoneses e brasileiros passam e passaram, fazendo parte do cenário da história das migrações internacionais.

Assim como houve mudanças e adoção dos costumes em geral, ampliação do vocabulário etc., no contato entre os imigrantes japoneses e os brasileiros no Brasil, também no Japão os brasileiros e japoneses elaboram diálogo e negociações culturais por meio das contribuições dadas pelos brasileiros em solo japonês. Essas circunstâncias mostram a importância do conhecimento do outro, do diferencial cultural existente, para a melhor compreensão, respeito sustentável e limites aceitáveis entre ambas as populações.

20. Alguns eventos de origem japonesa, como "Tanabata e Hana matsuri" já fazem parte do calendário da municipalidade de São Paulo.

21. Título do livro de Canclini (1998), estudioso argentino que discorre sobre 'hibridação' cultural dos países latino-americanos. 
Verificou-se, também, que as necessidades básicas dos seres humanos são semelhantes, independentemente do fator tempo.

O lazer, por sua vez, serviu para amenizar, tirar o estresse e dar alegria aos imigrantes japoneses no Brasil, promovendo sua aproximação do grupo dos iguais e também dos demais grupos étnicos. Já os brasileiros, no Japão, aproveitaram sua estada, principalmente para conhecer o país, valorizando, porém, o desenvolvimento das atividades sociais, do encontro com outros brasileiros na mesma situação, das relações sociais de amizade, e da formação do capital social. Intensificaram a aproximação com os japoneses, principalmente quando decidiram permanecer no país, interessando-se pela participação conjunta de atividades diversas nos momentos de lazer.

Portanto, verificou-se, no estudo, que o lazer, a educação informal e traços culturais se acham imbricados na formação do perfil dos brasileiros que permaneceram temporariamente no Japão, assim como foi observado entre os imigrantes japoneses no Brasil. São traços culturais que foram adaptados, assimilados e adotados, não por imposição, mas por meio do diálogo cultural entre as pessoas, de maneira natural e informal, processados nas sociedades endógenas e exógenas.

Bibliografia

CANCLINI, Néstor Garcia. Culturas Híbridas: Estratégias para entrar e sair da modernidade. São Paulo: EDUSP. 1998. 385p.

CARDOSO, Ruth Correa Leite. Estrutura familiar e mobilidade social. Estudo dos japoneses no Estado de São Paulo. São Paulo: Primus Comunicação. 1995. 196p.

DUMAZEDIER, Joffre. Lazer e cultura popular. São Paulo: Perspectiva, 1976. 333p. Vers une civilisation du loisir? France: Points Civilisation, 1972.

p. 26-28.

HANDA, Tomoo. 1973. Senso estético na vida dos imigrantes japoneses. In: SAITO, Hiroshi; MAEYAMA, Takashi. Assimilação e integração dos japoneses no Brasil. São Paulo: Vozes, p.386-413.

HANDA, Tomoo. 1987. O imigrante japonês. História de sua vida no Brasil. São Paulo: T.A Queiroz, 828p.

IKARI, Luci Tiho. “Lazer e tempo livre da comunidade nikkei na Região Metropolitana de São Paulo". ECA/USP, 2002. 171p.(Dissertação de Mestrado). 
KONO, Akira. "Empréstimos lingüísticos como reflexo do fenômeno 'Dekassegui" In: PELLEGRINI FILHO, Américo; YANAZE, Mitsuru Higuchi (Coord.). Encontros culturais Portugal-Japão-Brasil. Barueri, SP: Manole, 2002. p.197-207.

NAKASUMI, Tetsuo e YAMASHIRO, José. "O fim da era de imigração e a consolidação da nova colônia nikkei" In: Comissão de elaboração da história dos 80 anos da imigração japonesa no Brasil. Uma epopéia moderna, 80 anos da imigração japonesa no Brasil. São Paulo: Hucitec /Sociedade de Cultura Japonesa, 1992. p.417458.

NOGUEIRA, Arlinda Rocha. Imigração Japonesa na História contemporânea no Brasil. São Paulo: Centro de Estudos Nipo-brasileiros/Massao Ohno, 1984. 190p.

SAITO, Hiroshi. A integração e participação de japoneses e descendentes na sociedade brasileira. São Paulo: Centro de Estudos Nipo-brasileiros, 1977. Série A n.1, 25p.

SAITO, Hiroshi (org.). A presença japonesa no Brasil. São Paulo. T.A. Queiroz: USP, 1980. 236p.

VIEIRA, Francisca Isabel Schurig. $O$ japonês na frente de expansão paulista. São Paulo: Pioneira/USP, 1973. 270p.

WURMAN, Richard Saul. Ansiedade de informação: como transformar inform@ção em compreensão. São Paulo: Cultura Editores Associados, 1991. p.110-127. 